\title{
STRUCTURE, INTERACTIONS AND KINETICS OF RING-LIKE FORMATIONS OF CARBON NANOTUBES (NANOFIBERS) IN POLYMER NANOCOMPOSITES
}

\author{
Mikitaev Abdulah Kasbulatovich \\ Doctor of Chemical Sciences, Professor, \\ Kabardino-Balkarian State University named after H.M. Berbekov \\ I_dolbin@mail.ru \\ Chernyshevskogo St., 175, 360004 Nalchik, Russian Federation
}

Kozlov Georgiy Vladimirovich

Senior Researcher,

Kabardino-Balkarian State University named after H.M. Berbekov

I_dolbin@mail.ru

Chernyshevskogo St., 175, 360004 Nalchik, Russian Federation

\section{Zaikov Gennadiy Efremovich}

Doctor of Chemical Sciences, Professor,

Head of the Department of Biological and Chemical Physics of Polymers, Institute of Biochemical Physics named after N.M. Emanuel, RAS

chembio@sky.chph.ras.ru

Kosygina St., 4, 119334 Moscow, Russian Federation

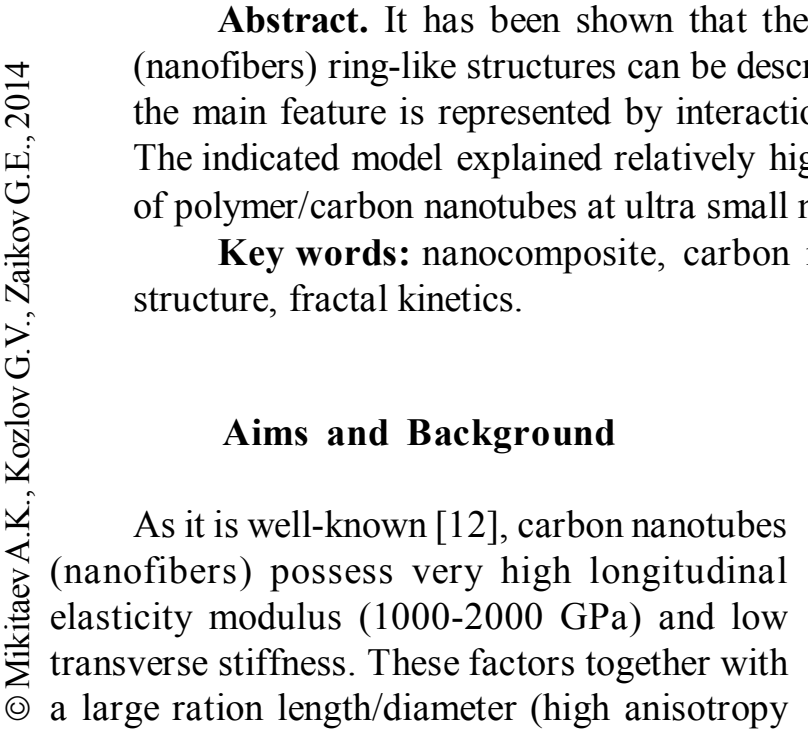

degree), typical for the indicated nanofillers, result in formation by them of ring-like structures, outwardly resembling macromolecular coils [13; 17]. This circumstance has already been noted in literature. So, the authors [13] assumed, that carbon nanotubes ring-like structures can be considered as macromolecular coils in 
semidiluted solutions. The authors [8] used Flory formula for rod-like macromolecules in case of carbon nanotubes percolation threshold in polymer nanocomposites determination. Nevertheless, such examples are rare enough and do not have systematic character.

It is obvious, that formation process of carbon nanotubes (nanofibers) ring-like structures can not be instantaneous for example in virtue of the polymer melt high enough viscosity, in which these structures are formed. Hence, the indicated process has definite duration, that makes necessary its kinetics study. Therefore purpose of the present work is the study of intercommunication of interactions, formation kinetics and structure of ringlike formations of carbon nanotubes (nanofibers) in polymer nanocomposites.

\section{Experimental}

Polypropylene (PP) “Kaplen” of mark 01030 was used as matrix polymer for the studied nanocomposites. This PP mark has a melt flow index of 2.3-3.6 g/10 min, molecular weight of $(2-3) \times 10^{5}$ and polydispersity index of 4.5 .

Carbon nanotubes (CNT) of mark "Taunite", having an external diameter of 20-70 nm, an internal diameter of 5-10 $\mathrm{nm}$ and length of $2 \mathrm{mcm}$ and more, were used as a nanofiller. In the studied nanocomposites $\mathrm{PP} / \mathrm{CNT}$ taunite content was varied within the limits of $0.25-3.0$ mass $\%$. Besides, the multiwalled nanofibers (CNF) were used, having a layers number of 20-30, diameter of 20-30 nm and length of the order of $2 \mathrm{mcm}$. In the nanocomposites $\mathrm{PP} / \mathrm{CNF} \mathrm{CNF}$ content $W_{n}$ was varied within the limits of 0.15-3.0 mass $\%$.

Nanocomposites PP/CNT and PP/CNF were prepared by the components mixing in melt on twin screw extruder Thermo Haake, model Reomex RTW 25/42, production of German Federal Republic. Mixing was performed at temperature 463-503 $\mathrm{K}$ and screw speed of $50 \mathrm{rpm}$ during $5 \mathrm{~min}$. Testing samples were prepared by casting under pressure method on a casting machine Test Samples Molding Apparate RR/TS MP of firm Ray-Ran (Taiwan) at temperature $503 \mathrm{~K}$ and pressure $43 \mathrm{MPa}$.

Uniaxial tension mechanical tests have been performed on the samples in the shape of two-sided spade with the sizes according to GOST 112 62-80. The tests have been conducted on the universal testing machine Gotech Testing Machine CT-TCS 2000, production of German Federal Republic, at temperature $293 \mathrm{~K}$ and strain rate of $\sim 2 \times 10^{-3} \mathrm{~s}^{-1}$.

\section{Results and Discussion}

CNT (CNF) ring-like structures radius $R_{\mathrm{CNT}}$ can be determined with the aid of the following percolation relationship [6]:

$$
\varphi_{n}=\frac{\pi L_{\mathrm{CNT}} r_{\mathrm{CNT}}^{2}}{\left(2 R_{\mathrm{CNT}}\right)^{3}},
$$

where $\varphi_{n}$ is nanofiller volume contents, $L_{\mathrm{CNT}}$ and $r_{\mathrm{CNT}}$ are length and radius of carbon nanotube (nanofiber), respectively.

The value $\varphi_{n}$ was calculated according to the well-known formula [11]:

$$
\varphi_{n}=\frac{W_{n}}{\rho_{n}},
$$

where $W_{n}$ is nanofiller mass contents, $\rho_{n}$ is its density, estimating for nanoparticles as follows [ibid.]:

$$
\rho_{n}=188\left(D_{\mathrm{CNT}}\right)^{1 / 3}, \mathrm{~kg} / \mathrm{m}^{3},
$$

where $D_{\mathrm{CNT}}$ is a carbon nanotube (nanofiller) diameter, which is given in $\mathrm{nm}$.

A CNT (CNF) ring-like formations structure can be characterized most exactly with the aid of its fractal dimension $D_{f}$, which is true structural characteristic, since it describes the distribution of $\mathrm{CNT}$ (CNF) ring-like formations elements in space [ibid.]. The value $R_{\mathrm{CNT}}$ calculation according to the equation (1) has shown its reduction at $\varphi_{n}$ growth. At the largest from the used $\varphi_{n}$ values, corresponding to $W_{n}=3.0$ mass $\%$, the indicated dependences have the tendency of asymptotic branch achievement, that supposes achievement by CNT or CNF ring-like structures of their $R_{\mathrm{CNT}}$ minimum values. By the analogy with macromolecular coils this means the achievement of maximally dense ring-like structure with the greatest limiting value of its fractal dimension $D_{f}\left(D_{f}^{\lim }\right)$, which is determined according to the equation [7]:

$$
D_{f}^{\lim }=\frac{4(d+1)}{7},
$$

where $d$ is the dimension of Euclidean space, in which a fractal is considered (it is obvious, in our case $d=3$ ). For $d=3$ the value $D_{f}^{\lim }=2.286$. 


\section{ТЕХНИКО-ТЕХНОЛОГИЧЕСКИЕ ИННОВАЦИИ}

Further for the value $D_{f}$ estimation the irreversible aggregation model can be used, which describes polymerization processes (macromolecular coil formation) and gives the following relationship for particles aggregates radius $R_{\text {agr }}$ determination [16]:

$$
R_{\text {agr }} \sim c_{0}^{-1 /\left(d-D_{f}\right)},
$$

where $c_{0}$ is aggregating particles initial concentration.

Coefficient in the relationship (5) can be determined at the following conditions: $R_{a g r}=R_{\mathrm{CNT}}, c_{0}=\varphi_{n}$ and $D_{f}=D_{f}^{\lim }$. The values $R_{\mathrm{CNT}}$ and $\varphi_{n}$ were accepted for $W_{n}=3.0$ mass $\%$. As the estimations according to the indicated relationship have shown, the value $D_{f}$ grows at $\varphi_{n}$ increasing ( $R_{\mathrm{CNT}}$ reduction) from 1.91 up to 2.29 for nanocomposites PP/CNT and from 1.76 up to 2.21 for nanocomposites $\mathrm{PP} / \mathrm{CNF}$.

As it is known [9], the process rate in fractallike medium is described by the following equation:

$$
\vartheta \sim t^{-h}
$$

where $t$ is process duration, $h$ is medium heterogeneity exponent $(0<h<1)$, which is transformed into zero for homoheneous samples only [ibid.].

The value $h$ was calculated according to the equation [10]:

$$
h=\frac{D_{f}-1}{2} .
$$

In Fig. 1 the dependences of $R_{\mathrm{CNT}}$ on CNT (CNF) ring-like structures formation process rate $\vartheta$ are adduced for the considered nanocomposites. As it was to be expected, the process rate $\vartheta$ increasing results in $R_{\mathrm{CNT}}$ growth, i.e. the value $\vartheta$ characterizes not CNT (CNF) rolling up in ringlike structures, but their unrolling. The dependence $R_{\mathrm{CNT}}(\vartheta)$ can be expressed analytically by the following empirical equations:

$$
R_{\mathrm{CNT}}=90+5.0 \times 10^{3} \vartheta
$$

for carbon nanotubes and

$$
R_{\mathrm{CNT}}=45+2.70 \times 10^{3} \vartheta
$$

for carbon nanofibers. The parameters $t$ in the equation (6) and $R_{\mathrm{CNT}}$ in the equations (8) and (9) are expressed in $\mathrm{s}$ and $\mathrm{nm}$, respectively.

Let us note, that the smallest $R_{\mathrm{CNT}}$ value according to the equations (8) and (9) is equal approximately to $2 D_{\mathrm{CNT}}$ at $\vartheta=0$, since for the obvious reasons the condition $R_{\mathrm{CNT}}=0$ is impossible. The greatest value $R_{\mathrm{CNT}}$ in case of homogeneous mediums $(h=0)$ is equal to $5090 \mathrm{~nm}$ for CNT and $2745 \mathrm{~nm}$ for CNF.

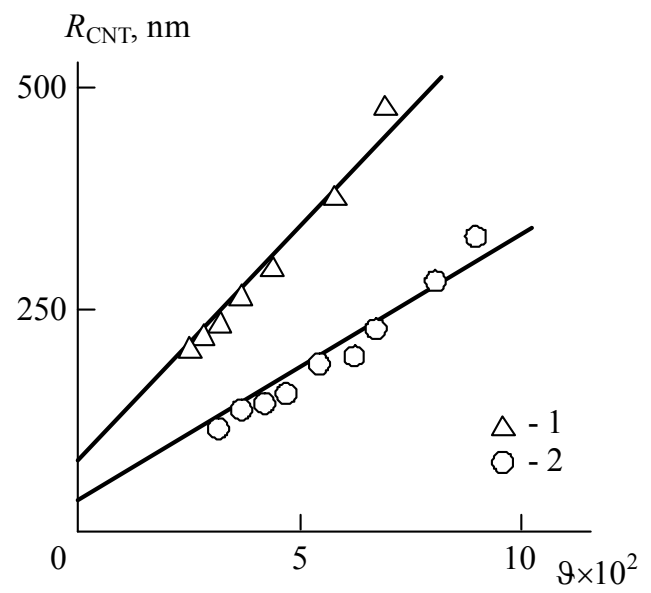

Fig. 1. The dependences of CNT (CNF) ring-like formations radius $R_{\mathrm{CNT}}$ on their unrolling rate $\vartheta$ for nanocomposites PP/CNT ( 1 ) and PP/CNF (2)

Let us consider the intercommunication of CNT (CNF) ring-like structures formation rate $\vartheta$ and interaction between them. At the indicated structure modeling as macromolecular coils the interaction between their elements and polymer matrix can be characterized by the parameter $\varepsilon$, determined as follows [10]:

$$
\varepsilon=\frac{2-D_{f}}{D_{f}} .
$$

For macromolecular coils the value $\varepsilon$ is varied within the limits of $-1 / 3 \div 1.0$. In the point $D_{f}=2.0$ parameter $\varepsilon$ changes its sign, that corresponds to the interactions type change from repulsion forces (positive $\varepsilon$ ) up to attraction forces (negative $\varepsilon$ ). In Fig. 2 the dependence of CNT (CNF) ring-like structures formation rate $\vartheta$ on interaction parameter $\varepsilon$ is adduced for the considered nanocomposites. As one can see, the linear dependence of CNT (CNF) ring-like structures unrolling rate $\vartheta$ at $\varepsilon$ increasing is obtained, i.e. the repulsion interaction intensification, which is described analytically by the following empirical equation:

$$
\vartheta=0.275(\varepsilon+0.215) .
$$

From the equation (11) it follows, that the value $\vartheta=0$ is achieved at $\varepsilon=-0.215$, i.e. at $D_{f}=2.548$. The greatest value $\vartheta=0.334$ is 
realized at $\varepsilon=1.0$, that corresponds to $h=0.192$ or $D_{f}=1.384$.

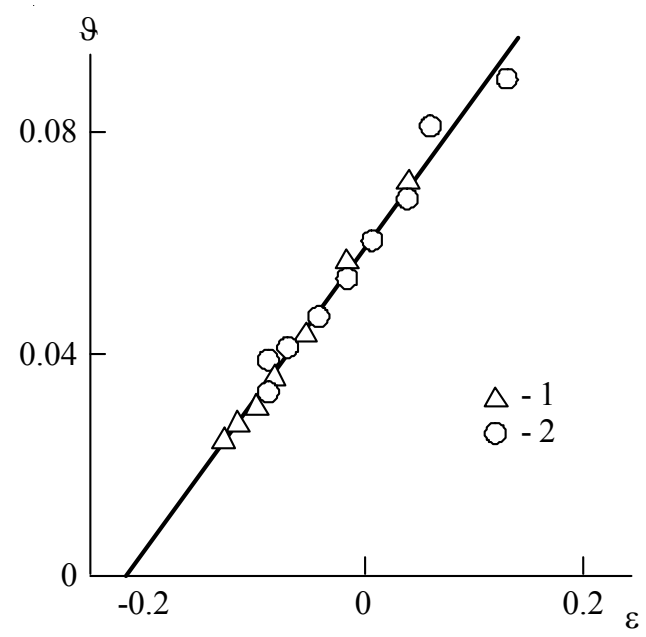

Fig. 2. The dependence of CNT (CNF) ring-like structures unrolling rate $\vartheta$ on interaction parameter $\varepsilon$ for nanocomposites PP/CNT (1) and PP/CNF (2)

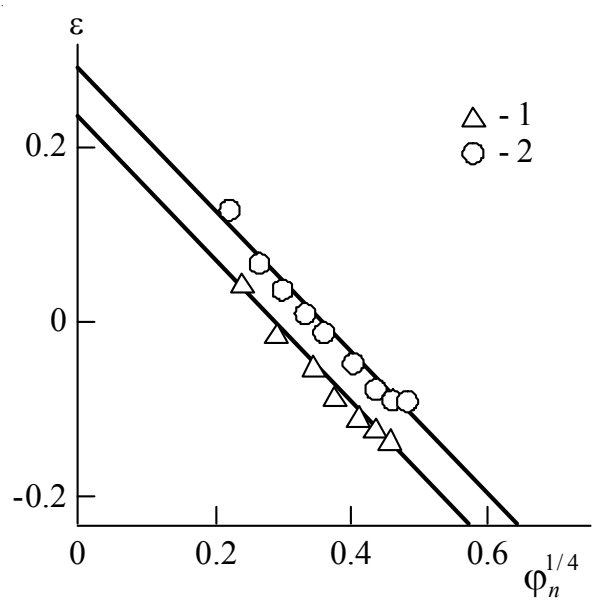

Fig. 3. The dependences of interaction parameter $\varepsilon$ on nanofiller volume contents $\varphi_{n}$ for nanocomposites PP/CNT (1) and PP/CNF (2)

As it is noted above, nanofiller contents $\varphi_{n}$ increasing results in dimension $D_{f}$ enhancement and, according to the equation (10), in the exponent $h$ increasing, i.e. in medium heterogeneity degree enhancement. In Fig. 3 the dependences of parameter $\varepsilon$ on the value $\varphi_{n}^{1 / 4}$ (such form of the indicated dependences was chosen for their linearization) are adduced for the considered nanocomposites. As one can see, $\varepsilon$ linear reduction is observed, i.e. the attraction interactions intensification, at nanofiller contents growth. This dependence can be expressed analytically by the following empirical equations:

$$
\varepsilon=0.25-0.85 \varphi_{n}^{1 / 4}
$$

for carbon nanotubes and

$$
\varepsilon=0.25-0.85 \varphi_{n}^{1 / 4}
$$

for carbon nanofibers.

The equations (11)-(13) combination demonstrates, that for the considered nanocomposites e variation is realized within the range, which is smaller than theoretical one for macromolecular coils $(\varepsilon=-1 / 3 \div 1.0)$, namely, within the limits of $\varepsilon=-0.215 \div 0.30$. The condition of full balance of attraction and repulsion forces for $\mathrm{CNT}$ (CNF) ring-like structures $\varepsilon=0$ is realized at $\varphi_{n}=0.0075$ for nanocomposites $\mathrm{PP} / \mathrm{CNT}$ and $\varphi_{n}=0.0155$ for nanocomposites $\mathrm{PP} / \mathrm{CNF}$.

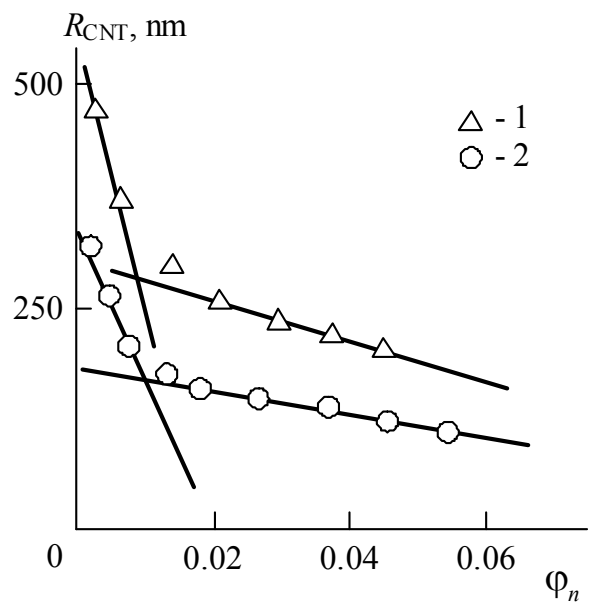

Fig. 4. The dependences of CNT (CNF) ring-like formations radius $R_{\mathrm{CNT}}$ on nanofiller volume contents $\varphi_{n}$ for nanocomposites PP/CNT (1) and $\mathrm{PP} / \mathrm{CNF}(2)$

In Fig. 4 the dependences $R_{\mathrm{CNT}}\left(\varphi_{n}\right)$ are adduced for the indicated nanocomposites, each one from which can be approximated by two straight lines with enough precision degree. The transition between these two parts of the dependences $R_{\mathrm{CNT}}\left(\varphi_{n}\right)$ corresponds to $\varphi_{n} \approx 0.0088$ for nanocomposites $\mathrm{PP} / \mathrm{CNT}$ and $\varphi_{n} \approx 0.0120$ for nanocomposites $\mathrm{PP} / \mathrm{CNF}$, that agrees well enough with the indicated above $\varphi_{n}$ values, at which the condition $\varepsilon=0$ is achieved or, in other words, with values $\varphi_{n}$, at which the 


\section{ТЕХНИКО-ТЕХНОЛОГИЧЕСКИЕ ИННОВАЦИИ}

transition from attraction interaction up to repulsion interactions of CNT (CNF) ring-like structures is realized. The linear dependences $R_{\mathrm{CNT}}\left(\varphi_{n}\right)$ slope is in about 15 times larger in case of the repulsion interactions in comparison with the attraction interactions. In other words, in case of interactions first type much more fast $R_{\mathrm{CNT}}$ growth at $\varphi_{n}$ reduction is observed, that influences positively on the characteristics of nanocomposites polymer/ carbon nanotubes [17]. This effect explains the indicated nanocomposites relatively high reinforcement degree at ultrasmall concentrations $\left(\varphi_{n} \leq 0.0015\right)$ of carbon nanotubes $[5 ; 8]$.

\section{Conclusions}

Thus, in the present work the results have shown that the formation (unrolling) rate of carbon nanotubes (nanofibers) ring-like structures in polymer nanocomposites can be described within the framework of fractal kinetics, where the indicated rate is defined by interactions level in these structures. A medium heterogeneity level or interactions degree and sign is controlled by nanofiller contents. The transition from attraction interactions up to repulsion interactions defines carbon nanotubes (nanofibers) ring-like structures radius fast growth, that results in nanocomposites relatively large reinforcement degree at ultrasmall contents of the indicated nanofillers.

\section{REFERENCES}

1. Bakhracheva Yu.S. Fracture Toughness Prediction by Means of Indentation Test. International Journal for Computational Civil and Structural Engineering, 2013, vol. 9, iss. 3, pp. 21-24.

2. Baron A.A, Bakhracheva Yu.S. A method for Impact Strength Estimation. Mechanika (Kaunas), 2007, vol. 66, no. 4, pp. 31-35.

3. Baron A.A, Bakhracheva Yu.S, Osipenko A.P. Fracture Toughness Estimation by Means of Indentation Test. Mechanika (Kaunas), 2007, vol. 67, no. 5, pp. 33-36.

4. Baron A.A., Gevlich D.S., Bakhracheva Yu.S. Specific Plastic Strain Energy as a Measure of the Cracking Resistance of Structural Materials. Russian metallurgy, 2002, no. 6, pp. 587-592.

5. Blond D., Barron V., Ruether M. et al. Enhancement of Modulus, Strength and Toughness in Poly(methyl methacrylate)-Based Composites by the Incorporation of Poly(methyl methacrylate)-
Functionalized Nanotubes. Advanced Functional Materials, 2006, vol. 16 (6), pp. 1608-1614.

6. Bridge B. Theoretical Modelling of the Critical Volume Fraction for Percolation Conductivity of FibreLoaded Conductive Polymer Composites. Journal of Materials Science Letters, 1989, vol. 8 (2), pp. 102-103.

7. Family F. Fractal Dimension and Grand Universality of Critical Phenomena. Journal of Statistical Physics, 1984, vol. 36, iss. 5-6, pp. 881-896.

8. Komarov B.A., Dzhavadyan E.A., Irzhak V.I., Ryabenko A.G., Lesnichaya V.A., Zvereva G.I., Krestinin A.V. Epoxy-Amine Composites With Ultralow Concentrations of Single-Layer Carbon Nanotubes. Polymer Science Series A, 2011, vol. 53, iss. 6, pp. 502-509.

9. Kopelman R. Excitons Dynamics Resembling Fractal One: Geometrical and Energetical Disorder. Pietronero L., Tosatti E., eds. Fractals in Physics. Amsterdam, Oxford, New York, Tokyo, North-Holland, 1986, pp. 524-527.

10. Kozlov G.V., Dolbin I.V., Zaikov G.E., eds. The Fractal Physical Chemistry of Polymer Solutions and Melts. Toronto, New Jersey, Apple Academic Press, 2014.316 p.

11. Mikitaev A.K., Kozlov G.V., Zaikov G.E. Polymer Nanocomposites: Variety of Structural Forms and Applications. New York, Nova Science Publishers Inc., 2009. 319 p.

12. Moniruzzaman M., Winey K.I. Polymer Nanocomposites Containing Carbon Nanotubes. Macromolecules, 2006, iss. 39 (16), pp. 5194-5205.

13. Schaefer D.W., Justice R.S. How Nano are Nanocomposites? Macromolecules, 2007, iss. 40 (24), pp. 8501-8517.

14. Semenova L.M., Bakhracheva Yu.S., Semenov S.V. Laws of Formation of Diffusion Layers and Solution of the Diffusion Problem in TemperatureCycle Carbonitriding of Steel. Metal Science and Heat Treatment, 2013, vol. 55, no. 1-2, pp. 34-37.

15. Shapochkin V.I., Semenova L.M., Bakhracheva Yu.S., Gyulikhandanov E.L., Semenov S.V. Effect of Nitrogen Content on the Structure and Properties of Nitrocarburized Steel. Metal Science and Heat Treatment, 2011, vol. 52, no. 9-10, pp. 413-419.

16. Shogenov V.N., Kozlov G.V. Fractal Clusters in Physics-Chemistry of Polymers. Chapter 2. Multicomponent Polymeric Materials. Apple Academic Press, 2013, pp. 13-47.

17. Yanovsky Yu.G., Kozlov G.V., Zhirikova Z.M., Aloev V.Z., Karnet Yu.N. Special Features of the Structure of Carbon Nanotubes in Polymer Composite Media. International Journal of Nanomechanics Science and Technology, 2012, vol. 3, iss. 2, pp. 99-124. 


\section{СТРУКТУРА, ВЗАИМОДЕЙСТВИЯ И КИНЕТИКА \\ КОЛЬЦЕОБРАЗНЫХ ОБРАЗОВАНИЙ УГЛЕРОДНЫХ НАНОТРУБОК (НАНОВОЛОКОН) В ПОЛИМЕРНЫХ НАНОКОМПОЗИТАХ}

\section{Микитаев Абдулах Касбулатович}

Доктор химических наук, профессор,

Кабардино-Балкарский государственный университет имени Х.М. Бербекова

I_dolbin@mail.ru

ул. Чернышевского, 175, 360004 г. Нальчик, Российская Федерация

\section{Козлов Георгий Владимирович}

Старший научный сотрудник,

Кабардино-Балкарский государственный университет имени Х.М. Бербекова I_dolbin@mail.ru

ул. Чернышевского, 175, 360004 г. Нальчик, Российская Федерация

\section{Заиков Геннадий Ефремович}

Доктор химических наук, профессор, заведующий отделом биологической и химической физики полимеров, Институт биохимической физики им. Н.М. Эмануэля РАН chembio@sky.chph.ras.ru ул. Косыгина, 4, 119334 г. Москва, Российская Федерация

Аннотация. В статье показано, что параметры формирования кольцеобразных образований углеродных нанотрубок (нановолокон) могут быть описаны в рамках фрактальной кинетики. В данном случае основной характеристикой указанного процесса являются взаимодействия в полимерной матрице на уровне нанонаполнителя. Описанная модель позволила объяснить относительно высокую степень связанности нанокомпозитов полимерных/углеродных нанотрубок при очень низком содержании нанонаполнителя.

Ключевые слова: нанокомпозит, углеродные нанотрубки (нановолокна), взаимодействия, кольцеобразная структура, фрактальная кинетика. 